\title{
Microbusinesses and Occupational Stress: Emotional Demands, Job Resources, and Depression Among Korean Immigrant Microbusiness Owners in Toronto, Canada
}

\author{
II-Ho Kim ${ }^{1,2}$, Samuel Noh ${ }^{2,3}$, Cyu-Chul Choi ${ }^{2,4}$, Kwame McKenzie ${ }^{3,5}$ \\ ${ }^{1}$ Department of Health Policy Research, Seoul Health Foundation, Seoul, Korea; ${ }^{2}$ Social and Epidemiological Research, Centre for Addiction and \\ Mental Health, Toronto, ON, Canada; ${ }^{3}$ Department of Psychiatry, University of Toronto, Toronto, ON, Canada; ${ }^{4}$ Western University Schulich School \\ of Medicine and Dentistry, Toronto, ON, Canada; ${ }^{5}$ Wellesley Institute, Toronto, ON, Canada
}

Objectives: While occupational stress has long been a central focus of psychological research, few studies have investigated how immigrant microbusiness owners (MBOs) respond to their unusually demanding occupation, or how their unresolved occupational stress manifests in psychological distress. Based on the job demands-resources model, this study compared MBOs to employees with regard to the relationships among emotional demands, job resources, and depressive symptoms.

Methods: Data were derived from a cross-sectional survey of 1288 Korean immigrant workers (MBOs, professionals, office workers, and manual workers) aged 30 to 70, living in Toronto and surrounding areas. Face-to-face interviews were conducted between March 2013 and November 2013.

Results: Among the four occupational groups, MBOs appeared to endure the greatest level of emotional demands, while reporting relatively lower levels of job satisfaction and job security; but MBOs reported the greatest job autonomy. The effect of emotional demands on depressive symptoms was greater for MBOs than for professionals. However, an inspection of stress-resource interactions indicated that though MBOs enjoyed the greatest autonomy, the protective effects of job satisfaction and security on the psychological risk of emotional demands appeared to be more pronounced for MBOs than for any of the employee groups.

Conclusions: One in two Korean immigrants choose self-employment, most typically in family-owned microbusinesses that involve emotionally taxing dealings with clients and suppliers. However, the benefits of job satisfaction and security may protect MBOs from the adverse mental health effects of job stress.

Key words: Microbusiness owners, Emotional demands, Job resources, Depressive symptoms, Korean immigrants, Canada

\section{INTRODUCTION}

Received: June 3, 2019 Accepted: August 2, 2019

Corresponding author: II-Ho Kim, PhD

Department of Health Policy Research, Seoul Health Foundation,

41 Manrije-ro 24-gil, Yongsan-gu, Seoul 04303, Korea

E-mail: kihsdh@hanmail.net

This is an Open Access article distributed under the terms of the Creative Commons Attribution Non-Commercial License (http://creativecommons.org/licenses/bync/4.0/) which permits unrestricted non-commercial use, distribution, and reproduction in any medium, provided the original work is properly cited.
The primary goal of this study is to augment the current research on job demands and resources as an important determinant of mental health by extending the discussion to immigrant microbusiness owners (MBOs). Specifically, this study examines psychological health variations related to emotional demands and 3 job resources (job autonomy, satisfaction, and security) by comparing immigrant MBOs and employees. Job demands are defined as physiological, psychological, and 
emotional aspects of a job that require workers' skills and continuous effort [1]. In particular, occupational stress theory posits that emotional demands are significantly harmful to workers' mental health, engendering conditions such as emotional exhaustion, burnout, and depression [2,3]. In fact, a large volume of empirical research has documented links between emotional demands and psychological problems among diverse employees, including managers, doctors, police officers, and home care workers [4-6]. In contrast to the growing knowledge on the harmful effects of emotional demands on employees, the evidence regarding immigrant MBOs is very limited. As frontline service workers, immigrant MBOs may be more vulnerable than immigrant employees to the health effects of emotional burdens [7]. They are mostly engaged in low-yield businesses with long work hours requiring a great deal of emotional regulation in daily interactions with customers $[8,9]$. Current research further suggests that the burden of emotional labour is not limited to the service sector [10].

Subsequent research has continued to support the job demands-resources (JD-R) model, according to which occupational resources such as job autonomy, job satisfaction, and job security may ultimately alleviate the psychological toll of occupational stress and improve workers' well-being [5,11]. In other words, high emotional demands and low job resources can exacerbate stress-induced psychological strain [12]. Accumulating evidence also suggests that results may differ across occupations and individual workers according to the level of occupational resources and the psychological meaning of resources $[13,14]$. Despite these arguments, occupational stress research has rarely examined the emotional demand-health link based on job resources among immigrant MBOs. In addition, employees with high levels of job resources are more inclined to deal successfully with highly demanding work conditions; however, it is still unknown whether the JD-R model also applies to immigrant MBOs. Being a business owner and working as one's own boss may generate psychological benefits related to having greater flexibility and autonomy than employees [15]. In the present study, we assessed job resources at the level of job autonomy, job satisfaction, and job security, since the typical measures of job resources such as social support from colleagues or supervisors are not applicable in a microbusiness setting [1]. This study is the first to investigate the interactive processes of emotional demands and occupational resources among immigrant $\mathrm{MBO}$ s in comparison to employees.

\section{METHODS}

Data for this study were obtained from the 2013 Ontario Korean Business Occupational Stress Study (OKBOSS), a crosssectional survey of first-generation Korean immigrant workers aged 30 to 70 living in the Greater Toronto Area and surrounding regions. The respondents were all foreign-born permanent residents or naturalized citizens of Canada who had been working in Canada for more than 2 years. After obtaining written consent from each of the total 1288 participants, face-toface interviews were carried out from March 2013 to November 2013. Since Korean immigrant business owners in Ontario are a hard-to-reach population for research, quota sampling was applied as the most viable method of data collection. The Ontario Korean Businessmen's Association directory was used to recruit MBOs. To increase representativeness, the MBO sample matched the employee sample in terms of age (30-70 years), sex, occupational groups, and regional distribution. Steps were taken to ensure that only 1 respondent per household and only 1 respondent per business was interviewed. Similarly, for employees, participation was restricted to only 1 worker per workplace for companies with fewer than $50 \mathrm{em}$ ployees, and 2 workers per workplace for companies with 50 employees or more. The final sample included 550 MBOs, 258 professionals, 223 office workers (non-manual), and 257 skilled/unskilled (manual) workers. Approximately $50 \%$ of the participants were from the Greater Toronto Area, while the remaining 50\% were from other regions of Southern Ontario, including the Hamilton-Niagara region and Owen Sound.

\section{Measurements}

\section{Depressive symptoms}

The Center for Epidemiologic Studies Depression (CES-D) scale was utilized to evaluate depressive symptoms experienced by participants. The CES-D, originally a 20 -item scale designed by the National Institute of Mental Health, measures 4 domains of depressive symptomatology: depressive mood, somatic symptoms, social withdrawal, and positive affect. However, several empirical studies revealed a cultural response bias for the positive affect items (i.e., happy, high selfesteem, hopeful, and joy in life) among certain Asian groups; therefore, for this study, the 4 positive items were eliminated. Each answer was rated on a 4-point Likert scale, ranging from 0 for rarely or none of the time (less than 1 day) to 3 for most or all of the time ( 5 days to 7 days a week). The overall scores 
ranged from 0 to 48, with a higher score indicating greater depressive symptoms. The 16-item CES-D scale had very good internal consistency, with a Cronbach's alpha of 0.926 .

\section{Emotional demands}

A 10-item emotional demand scale obtained from the previous literature was used to measure emotional demands $[6,7]$. The scale consisted of 4 aspects of emotional demands: the need to show positive or negative emotions ( 3 items), emotional sympathy ( 3 items), demand for sensitivity ( 3 items), and emotional suppression ( 2 items). Responses were selected on a 5-point Likert scale (never, rarely, sometimes, often, and always). We validated the unidimensional factor structure found in the entire sample and each occupational group, ensuring that the scale provided a short, valid measurement of emotional demands across the 4 occupational groups. The overall internal reliability was 0.883 , while for the various occupational groups, internal reliability ranged from 0.825 in the MBO group to 0.908 in the non-manual group.

\section{Occupational resources}

Occupational resources were measured by the following 3 commonly used scales: job authority, job satisfaction, and job security. The job autonomy scale consisted of 4 items: task control, decision-making responsibility, decision freedom, and work schedule flexibility. Each of the resource items was rated on a 4-point scale, ranging from 0 for "strongly disagree" to 3 for "strongly agree."The total summed scores of job autonomy ranged from 0 to 12 . The internal reliability was 0.74 .

Job satisfaction was measured by the Overall Job Satisfaction Scale of the Michigan Organizational Assessment Scale [16]. The 4 items measured fulfillment from work, willingness to choose the same job again, the job's meaningfulness, and future prospects. This scale was found to be reliable across a variety of occupational groups ( $\alpha=0.826$ ). In our study, perceived job security was measured with 2 questions related to the past and present maintenance of steady employment $(\alpha=0.426)$.

\section{Main independent variable and potential covariates}

Participants were divided into 4 occupational groups based on the International Standard Classification of Occupations. The professional group (reference) consisted of occupations including managers, accountants, engineers, nurses, dentists, teachers, and professors. The non-manual group was composed of jobs such as accounting assistants, clerical workers, operators, paralegals, and technicians. The manual group (skilled/unskilled) included auto-shop mechanics, repairers, drivers, home care workers, security officers, and manual labourers. MBOs operated businesses such as convenience stores, dry cleaners, restaurants, flower shops, hair or nail salons, shoe repair shops, and clothing stores.

Potential covariates included demographic factors, socioeconomic status, and years since immigration. Chronological age (30-70 years) and years since immigration were analysed as continuous variables. Marital status was collapsed into 2 groups, with currently married as the reference group and all others as the risk category. Pre-migration education attainment was divided into "completed high school or less" and "completed more than high school (reference)." Post-migration education was classified into "no" and "yes (reference)." Household income earned from all sources was analysed in terms of 8 income categories ranging from under US\$20 000 to US\$200 000 or more. Participants were divided into 3 groups based on annual household income: under US\$40 000, US\$40 000 to US\$79 999, and US\$80 000 or more (reference).

Occupational difficulties were measured by 2 variables: language barriers and working hours. To assess language barriers, participants were asked how often problems with English caused them to experience difficulties at work in the following situations: (1) completing tasks, (2) negotiating or interacting with others, (3) dealing with official documents, and (4) getting fair treatment from others (landlords, sales clerks, etc.). The summed scores ranged from 0 to 15 , with a higher score indicating greater language difficulties. The internal reliability was 0.899 . Working hours were measured as a continuous variable based on the average number of hours worked per week at the respondent's current job (20 hours or more).

\section{Statistical Analysis}

We took a 2-step analytical approach. First, using the chisquare test and analysis of variance, descriptive statistics were obtained to estimate the diverse characteristics of MBOs and employees (professionals, and non-manual and manual workers). Second, through multiple regression analyses, we tested a number of hypotheses derived from the occupational stress model and JD-R model for immigrant MBOs and employees. This test allowed us to evaluate whether the interaction terms produced significant differences among the occupational groups. All analyses were performed SAS version 9.4 (SAS Institute Inc., Cary, NC, USA). 


\section{Ethics Statement}

This study was approved by the Office of Research Ethics at the Centre for Addition and Mental Health (protocol \#119).

\section{RESULTS}

Table 1 shows the descriptive characteristics of the study sample of immigrant MBOs and employees. Each occupational group of immigrants made up approximately $20 \%$ of the total sample, except the MBO group (42.7\%). The sample consisted of similar proportions of males (51.3\%) and females (48.7\%). Approximately $87.7 \%$ of participants were married, whereas only $12.3 \%$ were never married or previously married. More than three-quarters of MBOs had a college or higher degree in their pre-migration education, but only $13.1 \%$ of them had earned post-migration educational certificates. In contrast, $62.4 \%$ of professionals, $56.9 \%$ of non-manual workers and $22.1 \%$ of manual workers had earned post-migration educational certificates in Canada. Approximately $29.6 \%$ of MBOs and $41.6 \%$ of manual workers reported annual household earnings of under US\$40 000, while only $8.5 \%$ of professionals and $18.4 \%$ of non-manual workers earned under US\$40 000 .

The mean age of participants was 49.7 years, and their mean length of residence in Canada was 16.3 years. Compared to other occupational groups, the MBO group was significantly older (53.6 years old) with longer terms of residence (17.2 years) in Canada.

MBOs worked the longest hours (58.8 hours per week), while other occupational groups worked an average of 40 hours per week. The overall mean score for emotional de-

Table 1. Socio-demographic characteristics according to occupational group

\begin{tabular}{|c|c|c|c|c|c|c|}
\hline Characteristics & Total & $\begin{array}{l}\text { Microbusiness } \\
\text { owners }\end{array}$ & Professionals & $\begin{array}{l}\text { Non-manual } \\
\text { workers }\end{array}$ & Manual workers & $p$-value \\
\hline Total & $1288(100)$ & $550(42.7)$ & $258(20.0)$ & $223(17.3)$ & $257(20.0)$ & \\
\hline Sex & & & & & & 0.001 \\
\hline Male & $661(51.3)$ & $293(53.3)$ & $146(56.6)$ & $111(49.8)$ & $111(43.2)$ & \\
\hline Female & $627(48.7)$ & $257(46.7)$ & $112(43.4)$ & $112(50.2)$ & $146(56.8)$ & \\
\hline Marital status & & & & & & 0.069 \\
\hline Not married & $159(12.3)$ & $25(4.5)$ & 49 (19.0) & $40(17.9)$ & $45(17.5)$ & \\
\hline Pre-migration education & & & & & & 0.673 \\
\hline High school or less & $350(27.2)$ & $130(23.6)$ & 77 (29.8) & 72 (32.3) & $71(27.6)$ & \\
\hline College or more & $938(72.8)$ & $420(76.4)$ & $181(70.2)$ & $151(67.7)$ & $186(72.4)$ & \\
\hline Post-migration education & & & & & & $<0.001$ \\
\hline$<40000$ & $333(25.8)$ & $163(29.6)$ & $22(8.5)$ & $41(18.4)$ & $107(41.6)$ & \\
\hline $40000-79999$ & $560(43.5)$ & $267(48.6)$ & $74(28.7)$ & $99(44.4)$ & $120(46.7)$ & \\
\hline$\geq 80000$ & $395(30.7)$ & $120(21.8)$ & $162(62.8)$ & $83(37.2)$ & $30(11.7)$ & \\
\hline Age & $49.72 \pm 8.96$ & $53.59 \pm 7.28$ & $45.62 \pm 8.56$ & $44.64 \pm 8.82$ & $49.95 \pm 8.80$ & $<0.001$ \\
\hline Years since immigration & $16.30 \pm 8.86$ & $17.16 \pm 8.75$ & $16.56 \pm 9.56$ & $15.94 \pm 8.44$ & $14.80 \pm 8.55$ & 0.005 \\
\hline Working hours & $48.29 \pm 15.03$ & $58.76 \pm 16.09$ & $40.87 \pm 6.60$ & $39.25 \pm 5.43$ & $41.15 \pm 9.84$ & $<0.001$ \\
\hline Language barriers & $4.72 \pm 3.69$ & $5.59 \pm 3.67$ & $3.16 \pm 3.18$ & $3.39 \pm 3.15$ & $5.60 \pm 3.72$ & $<0.001$ \\
\hline Emotional demands & $18.08 \pm 5.83$ & $19.69 \pm 4.40$ & $16.40 \pm 6.74$ & $16.52 \pm 6.63$ & $17.67 \pm 5.92$ & $<0.001$ \\
\hline Job autonomy & $7.68 \pm 2.50$ & $8.82 \pm 2.05$ & $8.08 \pm 2.13$ & $6.73 \pm 2.10$ & $5.66 \pm 2.47$ & $<0.001$ \\
\hline
\end{tabular}

Values are presented as number (\%) or mean \pm standard deviation. 
mands was 18.1, and MBOs were the most likely to face emotional demands (mean, 19.7). MBOs had the highest level of job autonomy and a modest level of job security, but a lower level of job satisfaction than other occupational groups. The mean depression score for Korean immigrant workers was 6.2, and MBOs and manual workers reported higher levels of depressive symptoms (mean, 6.4 and 7.4, respectively) than professionals and non-manual workers.

Table 2 presents the main effects of emotional demands

Table 2. Associations between emotional demands and depression according to occupational group

\begin{tabular}{|c|c|c|c|c|}
\hline Variables & Model 1 & Model 2 & Model 3 & Model 4 \\
\hline Intercept & $3.834^{*}$ & $4.870^{*}$ & $4.315^{*}$ & 1.783 \\
\hline Age & -0.046 & -0.037 & -0.033 & $-0.063^{*}$ \\
\hline \multicolumn{5}{|l|}{ Sex } \\
\hline Male & \multicolumn{4}{|c|}{ Reference } \\
\hline Female & $0.877^{*}$ & 0.142 & 0.269 & 0.367 \\
\hline \multicolumn{5}{|l|}{ Marital status } \\
\hline Married & \multicolumn{4}{|c|}{ Reference } \\
\hline Not married & $2.804^{* * *}$ & $2.774^{* * *}$ & $2.753^{* * *}$ & $2.857^{* * *}$ \\
\hline \multicolumn{5}{|l|}{ Occupation } \\
\hline Microbusiness owners & 0.890 & -0.059 & -0.085 & -0.767 \\
\hline Professionals & \multicolumn{4}{|c|}{ Reference } \\
\hline Non-manual workers & 0.077 & 0.263 & 0.282 & 0.351 \\
\hline Manual workers & 1.183 & 0.951 & 1.062 & 0.872 \\
\hline Years of immigration & 0.032 & 0.032 & 0.032 & $0.071^{*}$ \\
\hline \multicolumn{5}{|l|}{ Previous education } \\
\hline High school or less & -0.067 & 0.149 & 0.166 & -0.015 \\
\hline College or more & \multicolumn{4}{|c|}{ Reference } \\
\hline \multicolumn{5}{|l|}{ Canadian education } \\
\hline No & 0.866 & $1.099^{*}$ & 1.000 & 0.513 \\
\hline Yes & \multicolumn{4}{|c|}{ Reference } \\
\hline \multicolumn{5}{|l|}{ Annual income (US\$) } \\
\hline$\geq 80000$ & \multicolumn{4}{|c|}{ Reference } \\
\hline $40000-79999$ & $1.116^{*}$ & 0.508 & 0.624 & 0.532 \\
\hline$<40000$ & $2.300^{* * *}$ & $1.624^{* *}$ & $1.742^{* *}$ & $1.329^{*}$ \\
\hline Working hours & & & & $0.034^{*}$ \\
\hline Language barriers & & & & $0.305^{* * *}$ \\
\hline Emotional demands & & $0.245^{* * *}$ & $0.175^{* * *}$ & 0.159 \\
\hline \multicolumn{5}{|c|}{ Occupation*Emotional demands } \\
\hline Microbusiness owners & & & $0.145^{*}$ & 0.121 \\
\hline Non-manual workers & & & 0.020 & 0.023 \\
\hline Manual workers & & & 0.097 & 0.089 \\
\hline Ffor change in $R^{2}$ & 6.57 & 19.88 & 10.64 & 11.44 \\
\hline$R^{2}$ & 0.046 & 0.100 & 0.101 & 0.121 \\
\hline
\end{tabular}

All predictor variables were mean-centered. ${ }^{*} p<0.05,{ }^{* *} p<0.01,{ }^{* * *} p<0.001$. and occupational variations in the link between emotional demands and depressive symptoms among Korean immigrant workers. As shown in model 1, being female, not married, and low-income were significantly associated with higher levels of depressive symptoms. While emotional demands were likely to increase the risk of depressive symptoms (model 2), MBOs were more likely than employees to experience an increase in depressive symptoms with an increase in emotional demands $(\beta, 0.145 ; p<0.05 ;$ model 3$)$. After adding additional language barriers and work hours to model 4 , occupational variations in this link were no longer significant.

As shown in Table 3 (model 1), the 2-way interaction test (emotional demands by job resources) revealed that all 3 job resources significantly buffered the negative health effects of emotional demands: job autonomy $(\beta,-0.021 ; p<0.05)$, job satisfaction $(\beta,-0.027 ; p<0.01)$, and job security $(\beta,-0.070$; $p<0.001)$.

Model 2 shows the results of occupational variations in the buffering effect of job resources on the mental health risk of emotional demands. A 3-way interaction test (emotional demands by job resources by occupational status) showed that the buffering effects of job satisfaction and job insecurity were more prominent among MBOs than other occupational groups ( $\beta,-0.099 ; p<0.001$ for job satisfaction; $\beta,-0.298$; $p<0.001$ for job security; model 2) (Figure 1). However, there were no specific occupational variations in the buffering effect of job autonomy.

Figure 1 shows that the buffering effect of job security and job satisfaction on the health risk of emotional demands was more pronounced among MBOs than among professionals. However, the magnitude and direction of the buffering effect of job autonomy were higher among MBOs than among other occupational groups, but not to a significant extent.

\section{DISCUSSION}

Our analysis of the OKBOSS survey data compared immigrant MBOs and employees in terms of the relationships among emotional demands, occupational resources, and depressive symptoms. After controlling for demographic and socioeconomic factors, this study confirmed a positive relationship between emotional demands and depressive symptoms, which is fully consistent with previous findings [5,6,14]. However, immigrant MBOs face elevated levels of emotional demands and are the most vulnerable to the concomitant adverse mental 
Table 3. Associations among emotional demands, occupational resources, and depression according to occupational group

\begin{tabular}{|c|c|c|c|c|c|c|}
\hline \multirow{2}{*}{ Variables } & \multicolumn{2}{|c|}{ Job autonomy } & \multicolumn{2}{|c|}{ Job satisfaction } & \multicolumn{2}{|c|}{ Job security } \\
\hline & Model 1 & Model 2 & Model 1 & Model 2 & Model 1 & Model 2 \\
\hline Intercept & 1.716 & 2.348 & $3.119^{*}$ & 3.081 & 1.617 & 2.659 \\
\hline Age & $-0.073^{*}$ & $-0.077^{* *}$ & $-0.073^{*}$ & $-0.077^{* *}$ & $-0.057^{*}$ & $-0.063^{*}$ \\
\hline \multicolumn{7}{|l|}{ Sex } \\
\hline Male & \multicolumn{2}{|c|}{ Reference } & \multicolumn{2}{|c|}{ Reference } & \multicolumn{2}{|c|}{ Reference } \\
\hline Female & 0.073 & 0.217 & 0.502 & 0.655 & 0.505 & 0.624 \\
\hline \multicolumn{7}{|l|}{ Marital status } \\
\hline Married & \multicolumn{2}{|c|}{ Reference } & \multicolumn{2}{|c|}{ Reference } & \multicolumn{2}{|c|}{ Reference } \\
\hline Not married & $2.728^{* * *}$ & $2.678^{* * *}$ & $2.902^{* * *}$ & $2.780^{* * *}$ & $2.898^{* * *}$ & $2.850 * * *$ \\
\hline Years of immigration & $0.070^{*}$ & $0.071^{*}$ & $0.064^{*}$ & $0.062^{*}$ & $0.071^{*}$ & $0.069^{*}$ \\
\hline \multicolumn{7}{|l|}{ Previous education } \\
\hline High school or less & -0.163 & -0.081 & -0.011 & -0.062 & -0.210 & -0.156 \\
\hline College or more & \multicolumn{2}{|c|}{ Reference } & \multicolumn{2}{|c|}{ Reference } & \multicolumn{2}{|c|}{ Reference } \\
\hline \multicolumn{7}{|l|}{ Canadian education } \\
\hline No & 0.452 & 0.399 & 0.271 & 0.170 & 0.469 & 0.494 \\
\hline Yes & \multicolumn{2}{|c|}{ Reference } & \multicolumn{2}{|c|}{ Reference } & \multicolumn{2}{|c|}{ Reference } \\
\hline \multicolumn{7}{|l|}{ Annual income (US\$) } \\
\hline$\geq 80000$ & \multicolumn{2}{|c|}{ Reference } & \multicolumn{2}{|c|}{ Reference } & & \\
\hline $40000-79999$ & 0.355 & 0.489 & 0.204 & 0.303 & -0.105 & -0.059 \\
\hline$<40000$ & $1.174^{*}$ & $1.295^{*}$ & 0.989 & $1.083^{*}$ & 0.435 & 0.550 \\
\hline Occupation & & & & & & \\
\hline Microbusiness owners & -0.349 & -0.571 & $-2.254^{* * *}$ & $-1.718^{*}$ & -0.809 & -0.754 \\
\hline Professionals & & & & & & \\
\hline Non-manual workers & -0.121 & -0.143 & -0.396 & 0.073 & -0.001 & 0.154 \\
\hline Manual workers & 0.100 & -0.377 & -1.137 & -0.622 & -0.132 & 0.046 \\
\hline Working hours & $0.041^{*}$ & $0.044^{* *}$ & $0.033^{*}$ & $0.036^{*}$ & $0.034^{*}$ & $0.033^{*}$ \\
\hline Language barriers & $0.282^{* * *}$ & $0.272^{* * *}$ & $0.257^{* * *}$ & $0.259^{* * *}$ & $0.239 * * *$ & $0.228^{* * *}$ \\
\hline Emotional demands & $0.221^{* * *}$ & $0.168^{* *}$ & $0.219^{* * *}$ & 0.026 & $0.222 * * *$ & $0.171 * *$ \\
\hline Job resources & $-0.363^{* * *}$ & -0.229 & $-0.728^{* * *}$ & $-0.592^{* *}$ & $-1.563^{* * *}$ & $-1.081^{* *}$ \\
\hline Emotional demands* Resources & $-0.021^{*}$ & -0.004 & $-0.027^{* *}$ & 0.033 & $-0.070^{* * *}$ & -0.010 \\
\hline Occupation*Emotional demands & & & & & & \\
\hline Microbusiness owners & & $0.192^{*}$ & & $0.189 * *$ & & -0.010 \\
\hline Non-manual workers & & -0.013 & & $0.166^{*}$ & & 0.109 \\
\hline Manual workers & & -0.014 & & $0.205^{* *}$ & & 0.016 \\
\hline Occupation* Job resources & & & & & & \\
\hline Microbusiness owners & & 0.047 & & 0.012 & & -0.103 \\
\hline Non-manual workers & & -0.146 & & -0.170 & & 0.092 \\
\hline Manual workers & & -0.448 & & -0.189 & & -0.760 \\
\hline Occupation*Demands* Resource & & & & & & \\
\hline Microbusiness owners & & -0.057 & & $-0.099 * * *$ & & $-0.298^{* * *}$ \\
\hline Non-manual workers & & -0.014 & & -0.062 & & 0.017 \\
\hline Manual workers & & -0.047 & & -0.034 & & 0.013 \\
\hline Ffor change in $R^{2}$ & 13.45 & 9.25 & 19.23 & 12.23 & 19.38 & 14.15 \\
\hline$R^{2}$ & 0.134 & 0.138 & 0.185 & 0.179 & 0.186 & 0.203 \\
\hline
\end{tabular}

All predictor variables were mean-centered.

${ }^{*} p<0.05,{ }^{* *} p<0.01,{ }^{* * *} p<0.001$. 

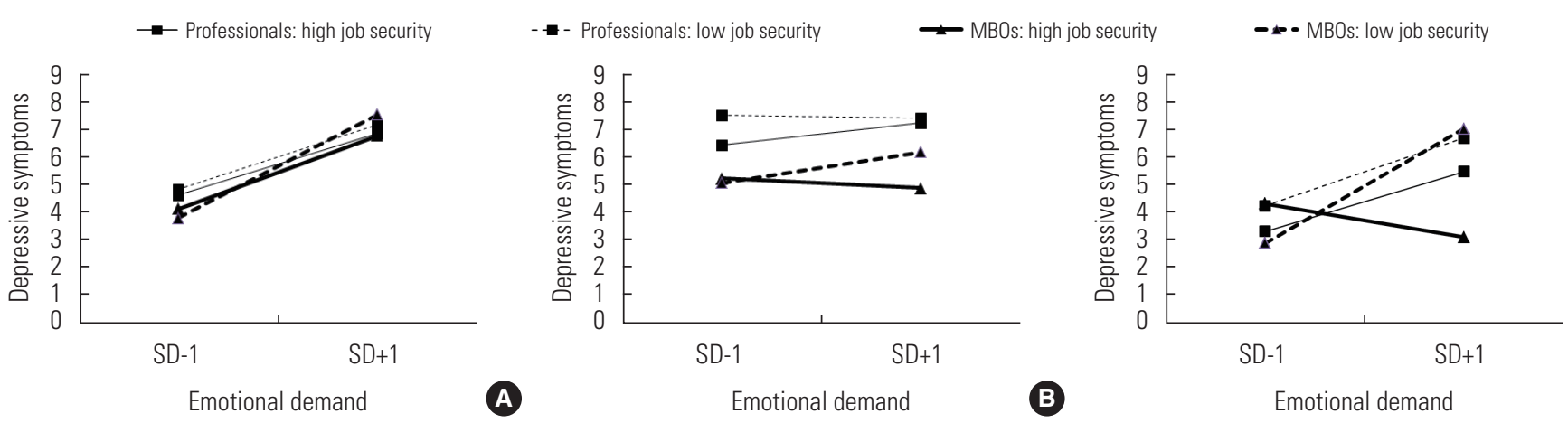

Figure 1. The moderating effect of job resources on the association between emotional demands and depressive symptoms (A) job autonomy, (B) job satisfaction, and (C) job security. The buffering effects of 3 types of occupational resources on the relationship between emotional demandss and depressive symptoms among professionals and MBOs. The other occupational groups such as non-manual and manual workers, which followed a pattern similar to that of the professional group, have been omitted. The low and high occupational resource effects are depicted with standard scores of 1 SD below (SD-1) and above (SD+1) the mean, respectively. MBOs, microbusiness owners; SD, standard deviation.

health problems among occupational groups [9,17]. Our study revealed that the substantially higher perception of emotional demands and accompanying greater health risk among immigrant MBOs stemmed from their difficult work environment, particularly their long working hours, and language-related challenges. In this study, MBOs reported working an average of 58.8 hours per week, while employees worked on average 40 hours per week. In North America, Korean immigrant MBOs are known to work the longest hours compared to immigrant employees and MBOs of other ethnicities $[9,18]$. In comparison to immigrant professionals and office workers, immigrant $\mathrm{MBOs}$ also appear to struggle more with language problems, reporting difficulties in completing tasks at work, interacting with others, and dealing with official documents. A qualitative study conducted in the USA illustrated that a lack of language proficiency elevated business-related stress and engendered psychological distress, while proper communication was an important asset in service businesses [19].

In line with the JD-R model, our findings show that all 3 types of occupational resources (autonomy, satisfaction, security) seemed to play a crucial role in buffering the negative effects of emotional demands on depressive symptoms among Korean-Canadian workers. This study's findings are in agreement with assumptions and empirical evidence from earlier studies on occupational distress $[11,20]$. Job resources such as autonomy, satisfaction, and security are closely related to motivation and can stimulate performance and increase productivity, which in turn can result in desired health outcomes, such as lower job accidents and greater well-being [21,22].
The self-determination theory also describes how job autonomy and job engagement mitigate the psychological toll of high job demands [11,23].

In this present study, however, the beneficial effects seemed to be significantly more pronounced for immigrant MBOs than employees. In particular, when MBOs felt a strong sense of job satisfaction and security, the effects of emotional demands on depressive symptoms were no longer significant (Figure 1). Despite experiencing the highest levels of emotional demands, when MBOs fulfill their financial goals and achieve security, they may be more likely than employees to improve their mental health and wellbeing $[11,20]$. Nonetheless, job autonomy was not enough to reduce the psychological impact of emotional demands for either immigrant MBOs or employees, even though MBOs appeared to enjoy the highest level of job autonomy. Similar findings were reported in a recent meta-analytic review of 106 studies [24], despite a substantial body of empirical research reporting a buffering role of job autonomy on the demand-health link [25]. Warr [26]'s vitamin theory of job resources is noteworthy: similar to the intoxication effect of an overdose of vitamins, high levels of job autonomy can cause a high risk of emotional exhaustion. It is highly plausible that employees with higher job autonomy may also feel burdened by their high responsibility or have difficulty with decision-making. Indeed, several empirical studies support this argument, suggesting an inverted Ushape pattern between job resources and health $[3,12]$. In our study, however, the buffering roles of job autonomy were trivial not only among professionals and MBOs with high autono- 
my, but also among all employees, including non-manual and manual workers with low autonomy. The discrepancy across results indicates that the potential moderating effects of job resources can vary across occupations, working populations, and job environments.

The present study has several limitations. First, data were collected through convenience sampling targeting Korean Canadian immigrants, so it may not be possible to generalize the findings to the whole immigrant population in Canada. Second, the data on work characteristics such as emotional demands and job resources were collected by self-reporting, which may involve a reporting bias. However, the consistency of this study's findings according to the JD-R model suggests that the composite index may not be a major drawback in this study. Third, caution should be taken when interpreting the dimensionality of the 16-item CES-D. Despite its lack of diagnostic validity, this 16-item CES-D scale appears useful and valid in screening study participants for depressive symptoms for hypothesis-testing among certain Asian groups [27]. Finally, due to an inadequate sample size, we could not consider specific occupations that may suffer from high levels of emotional demands, to compare the health consequences of emotional demands among MBOs; instead occupational status was categorized into 4 broad occupational groups (MBOs and professional, non-manual, and manual employees). Nonetheless, this study provides unique findings comparing the work stressors and resources of MBOs to those of employees, whereas there is a significant volume of literature and empirical studies illustrating the link between job demands and their health consequences in a wide range of occupations.

In conclusion, our study shows that $\mathrm{MBO}$ s experienced greater emotional demands, and their adverse impact on mental health was more marked for MBOs than for employees. Notably, the highest risk of depressive symptoms from emotional demands among MBOs was attributable to their long working hours and high level of language difficulties. Even though emotional demands are a crucial factor harming the psychological health of MBOs, the effectiveness of job satisfaction and security in compensating for such negative health effects is greater among MBOs than employees.

\section{CONFLICT OF INTEREST}

The authors have no conflicts of interest associated with the material presented in this paper.

\section{ACKNOWLEDGEMENTS}

This research project was supported by the Canadian Institutes of Health Research in 2013.

\section{AUTHOR CONTRIBUTIONS}

Conceptualization: IHK, SN. Data curation: IHK, SN. Funding acquisition: IHK, SN, KM. Formal analysis: IHK, CC. Methodology: IHK, CC. Writing - original draft: IHK. Writing - review \& editing: IHK, SN, CC, KM.

\section{ORCID}

II-Ho Kim https://orcid.org/0000-0002-6202-4353

Samuel Noh https://orcid.org/0000-0001-6748-5223

Cyu-Chul Choi https://orcid.org/0000-0002-9241-1653

Kwame McKenzie https://orcid.org/0000-0001-6419-8130

\section{REFERENCES}

1. Schaufeli WB, Bakker AB. Job demands, job resources, and their relationship with burnout and engagement: a multi-sample study. J Organ Behav 2004;25(3):293-315.

2. Centers for Disease Control and Prevention. National Institute for Occupational Safety and Health (NIOSH) publications and products: stress at work; 1999 [cited 2019 Jun 1]. Available from: https://www.cdc.gov/niosh/docs/99-101/default.html.

3. Bakker AB, Demerouti E, Euwema MC. Job resources buffer the impact of job demands on burnout. J Occup Health Psychol 2005;10(2):170-180.

4. Lewig KA, Dollard MF. Emotional dissonance, emotional exhaustion and job satisfaction in call centre workers. Eur J Work Organ Psychol 2003;12(4):366-392.

5. de Jonge J, Le Blanc PM, Peeters MC, Noordam H. Emotional job demands and the role of matching job resources: a crosssectional survey study among health care workers. Int J Nurs Stud 2008;45(10):1460-1469.

6. Kim IH, Noh S, Muntaner C. Emotional demands and the risks of depression among homecare workers in the USA. Int Arch Occup Environ Health 2013;86(6):635-644.

7. Zapf D, Vogt C, Seifert C, Mertini H, Isic A. Emotion work as a source of stress: the concept and development of an instrument. Eur J Work Organ Psychol 1999;8(3):371-400.

8. Parslow RA, Jorm AF, Christensen H, Rodgers B, Strazdins L, 
D'Souza RM. The associations between work stress and mental health: a comparison of organizationally employed and self-employed workers. Work Stress 2004;18(3):231-244.

9. Teixeira C, Lo L, Truelove M. Immigrant entrepreneurship, institutional discrimination, and implications for public policy: a case study in Toronto. Environ Plan C Gov Policy 2007;25(2): 176-193.

10. Olsson E, Ingvad B. The emotional climate of care-giving in home-care services. Health Soc Care Community 2001;9(6): 454-463.

11. Demerouti E, Bakker AB, Nachreiner F, Schaufeli WB. The job demands-resources model of burnout. J Appl Psychol 2001; 86(3):499-512.

12. De Jonge J, Schaufeli WB. Job characteristics and employee well-being: a test of Warr's Vitamin Model in health care workers using structural equation modelling. J Organ Behav 1998; 19(4):387-407.

13. Theorell T, Karasek RA. Current issues relating to psychosocial job strain and cardiovascular disease research. J Occup Health Psychol 1996;1(1):9-26.

14. Brotheridge CM, Grandey AA. Emotional labor and burnout: comparing two perspectives of "people work". J Vocat Behav 2002;60(1):17-39.

15. Baldwin J, Bian L, Dupuy R, Gellatly G. Failure rate for new Canadian firms, new perspectives on entry and exit. Ottawa: Statistics Canada; 2000, p. 43-48.

16. Lawler E, Cammann C, Nadler D, Jenkins D. Michigan organizational assessment questionnaire. Washington, DC: American Psychological Association; 1979.

17. Baldwin J, Gray T, Johnson J, Proctor J, Rafiquzzaman M, Sabourin D. Failing concerns, business bankruptcy in Canada. Ot- tawa: Statistics Canada; 1997, p. 23-31.

18. Min PG. Problems of Korean immigrant entrepreneurs. Int Migr Rev 1990;24(3):436-455.

19. Kang M. The managed hand: the commercialization of bodies and emotions in Korean immigrant-owned nail salons. Gend Soc 2003;17(6):820-839.

20. Dekker SW, Schaufeli WB. The effects of job insecurity on psychological health and withdrawal: a longitudinal study. Aust Psychol 1995;30(1):57-63.

21. Brown C, Reich M, Stern D. Becoming a high-performance work organization: the role of security, employee involvement, and training; 1992 [cited 2019 Jun 1]. Available from: http://irle. berkeley.edu/workingpapers/45-92.pdf.

22. Ilardi BC, Leone D, Kasser T, Ryan RM. Employee and supervisor ratings of motivation: main effects and discrepancies associated with job satisfaction and adjustment in a factory setting 1. J Appl Soc Psychol 1993;23(21):1789-1805.

23. Deci E, Ryan RM. Intrinsic Motivation and self-determination in human behavior. New York: Springer; 1985, p. 9-10.

24. Luchman JN, González-Morales MG. Demands, control, and support: a meta-analytic review of work characteristics interrelationships. J Occup Health Psychol 2013;18(1):37-52.

25. Bakker AB, Demerouti E, De Boer E, Schaufeli WB. Job demands and job resources as predictors of absence duration and frequency. J Vocat Behav 2003;62(2):341-356.

26. Warr P. Work, unemployment, and mental health. New York: Oxford University Press; 1987, p. 9-14.

27. Noh S, Kaspar V, Chen X. Measuring depression in Korean immigrants: assessing validity of the translated Korean version of CES-D scale. Cross Cult Res 1998;32(4):358-377. 